\title{
ENZYMATICALLY SYNTHESIZED pH-RESPONSIVE IPN FOR IN-SITU RELEASE OF PANTOPRAZOLE SODIUM
}

\author{
SARUCHI SHARMA ${ }^{*}$, VANEET KUMAR ${ }^{2}$
}

\author{
${ }^{* 1}$ Department of Biotechnology, CT Group of Institutions, Shahpur Campus, Punjab, India, ${ }^{2}$ Department of Applied Sciences, CT Group of \\ Institutions, Shahpur Campus, Punjab, India \\ Email: suruchinitj15@gmail.com
}

Received: 28 Nov 2018 Revised and Accepted: 01 Mar 2019

\begin{abstract}
Objective: This study involves the synthesis of Gum tragacanth (gt) based interpenetrating polymer network (ipn) and its utilization for sustained release of anti-ulcerative drug i.e. pantoprazole sodium.
\end{abstract}

Methods: IPN was synthesized from Gum tragacanth, polyacrylic acid (gt-cl-paa) hydrogel. gt-cl-paa was kept in distilled water. Further, acryamide (aam) and methylmethacrylate (mma) was added and then kept for overnight. Later on, lipase and glutaraldehyde were added. Homopolymers and the unreacted monomers were removed using acetone. Synthesized IPN was dried at $50{ }^{\circ} \mathrm{C}$ for further study.

Synthesized ipn was swelled in water and the drug was added to it. The drug was entrapped in the pores of the synthesized ipn and then drug release behavior was studied using uv-vis spectrophotometer.

Results: Gt, paa and mma based crosslinked IPN were synthesized using lipase-glutaraldehyde as initiator-crosslinker system. The synthesized IPN was $\mathrm{pH}$ sensitive and possessed the desired swelling capacity required for the controlled and systematic liberation of pantoprazole sodium at $37{ }^{\circ} \mathrm{C}$. The kinetic of drug release was studied and found that lateral diffusion $\left(D_{L}\right)$ of drug was higher as compared to the initial diffusion $\left(D_{I}\right)$. The prepared IPN can be used as prospective carrier for prolonged drug delivery.

Conclusion: A novel pH sensitive and colon targeted IPN was synthesized. It acts as an effective device for the controlled release of drug pantoprazole sodium.

Keywords: Interpenetrating polymer network (ipn), Drug delivery, Methylmethacrylate and pantoprazole sodium

(C) 2019 The Authors. Published by Innovare Academic Sciences Pvt Ltd. This is an open access article under the CC BY license (http://creativecommons.org/licenses/by/4.0/) DOI: http://dx.doi.org/10.22159/ijpps.2019v11i4.31043

\section{INTRODUCTION}

Colon-specific drug delivery is considered as one of the essential sectors nowadays across the globe. Cure of colonic ailments, for example Crohn's ailment, ulcerative colitis etc. requires colon targeted drug release device. Colonic drug delivery system needed a time-consuming release of the drug in the stomach and in the intestine faster release of the drug. Best options for this is to use $\mathrm{pH}$ responding smart materials, timed specific release and utilization of pro-drug $[1,2]$.

Today research study has been centered on the preparation of ipn system as they have superior characteristics than that of the individual monomers from which it is formed. Today's demands cannot be achieved with homopolymer and grafted product [3-6]. As the requirements have increased both in the case of properties and performances, interpenetrating polymeric network (ipn) fulfill all the above demands. ipn hydrogels comprised of two or more than two polymer chains that are made by the proximity of each other. These have been found to be resourceful for different applications. The characteristics of ipn-system such as porous behavior, flexibility and reaction to stimuli can be exploited in the different sectors like pharmaceutical, agriculture, biomedical etc. [7-10].

The ability to hold a significant quantity of water content makes IPN flexible and resembles the biological tissues [11-14]. The diffusion of the molecules is specific from the IPN matrix. IPN matrix responds to the change in temperature, $\mathrm{pH}$, electric and magnetic fields. Its spongy characteristics permit easy loading of drugs into the ipn and consequent discharge of the drug at a determined pace and at a particular interval of time [15-17]. Such characteristics of the ipn beneficial to use them as a device for regulated liberation of the drugs. The gastro-intestinal (gi) liberation of sodium diclofenac has carried out through chitosan/polyethylene glycol hydrogel beads. Researchers are working on the $\mathrm{pH}$ sensitive and glucose-sensitive insulin release through hydrogels both in vitro and in vivo [18-21].
Gum tragacanth (gt) is an anionic polysaccharide that contains two main parts: one is $\mathrm{H}_{2} \mathrm{O}$ soluble and other is $\mathrm{H}_{2} \mathrm{O}$ swellable. Both the portions can be easily separated. Bassorin and tragacanthin composition differ notably regarding their contents of uronic acid and methoxyl [22-24].

The current study comprised of synthesis of new IPN based on $g t$, aa, aam and mma, crosslinked with glutaraldehyde and catalyzed by enzyme lipase and studied as the possible GI drug delivery device for the model drug employing, pantoprazole sodium.

The novelty of the present work lies on that a green method i.e. enzyme was used instead of chemical initiator for the synthesis of ipn. Natural polysaccharide gt was modified for the synthesis of ipn. gt based product was already in used in food industry, thus no harsh effect for synthesizing IPN based drug delivery device. The synthesized ipn respond to the external $\mathrm{pH}$, thus effective for the controlled release of pantoprazole sodium in the gi tract.

The synthesized matrix contains both hydrophilic and hydrophobic chains. Moreover, hydrophobic part helps in the controlled liberation of the drug from the matrix. Thus, the ipn matrix is the promising approach for the in vitro release of the drug. It improves the assimilation of pantoprazole sodium in the gi tract for a prolonged time. Pantoprazole sodium is an acid-labile drug and is effective when absorbed in the gi tract. Therefore, drug liberation was studied at different $\mathrm{pH}$.

\section{MATERIALS AND METHODS}

\section{Chemicals}

$g t$, glutaraldehyde, aa, aam and mma (MERCK), India, Lipase (MP Biomedia). FTIR of the gt and IPN were recorded on Perkin spectrophotometer by $\mathrm{KBr}$ pellet method. SEM was taken on LEO435VF. uv-vis spectrophotometer (Systronics, 2201) was used to 
study the pantoprazole sodium liberation rate through the IPN. Thermal analysis of the samples were studied through TG/DTA 6300 , in nitrogen with $10^{\circ} \mathrm{C} / \mathrm{min}$ heating rate.

\section{Enzymatic synthesis of IPN}

Initially, the $g t$ and aa based hydrogel was synthesized by following the method reported in our previous publication [25]. For the preparation of ipn, the already prepared hydrogel of gt and AA i.e. gt-cl-paa was swelled in the distilled water. Further, aam and mma were added and kept for overnight. Later on, lipase and glutaraldehyde were added. Homopolymers and the unreacted monomers were removed using acetone. Synthesized ipn was dried at $50{ }^{\circ} \mathrm{C}$ until stable weight (wt.) was obtained. Percentage swelling (Ps) is the criteria for optimizing the reaction parameters. The $\mathrm{P}_{s}$ was determined with the help of the mathematical equation given below [25].

$$
P_{s}=\frac{W_{s}-W_{d}}{W_{d}} \times 100
$$

Where, $W_{s}$ is the wt. of swollen ipn and $W_{d}$ is the weight of dry IPN.

\section{Drug release behavior of ipn}

The drug loading i.e. pantoprazole sodium drug molecules into the IPN and investigation of the drug liberation mechanism from the ipn polymer matrix was studied by the method reported in the literature [26-29].

\section{RESULTS AND DISCUSSION}

\section{Enzymatic synthesis of the ipn}

\section{Synthesis of the gt-cl-paa}

Different reaction parameters viz. reaction time, treatment temperature, solvent, $\mathrm{pH}$, concentration of lipase, aam, mma and glutaraldehyde were optimized to get the product with maximum $\mathrm{P}_{\mathrm{s}}$ [25]. The effect of these parameters on $P_{s}$ was studied one by one. The optimized reaction parameter to get the maximum $\mathrm{P}_{\mathrm{s}}$ are reaction time $=48 \mathrm{~h}$, reaction temperature $=40^{\circ} \mathrm{C}$, amount of water $=4 \mathrm{ml}, \mathrm{pH}=5.0$, concentration of lipase $=0.03 \times 10^{-6} \mathrm{molL}^{-1}$, aa concentration $=1.459 \times 10^{-4} \mathrm{~mol} / \mathrm{l}$, glutaraldehyde concentration $=$ $10.61 \times 10^{-6} \mathrm{~mol} / \mathrm{l}$, aam concentration $1.352 \times 10-3 \mathrm{~mol} / \mathrm{l}$ [25].

\section{Optimization of MMA}

The optimum concentration of mma for maximum $P_{s}(258.9 \%)$ was found to be $2.45 \times 10^{-3} \mathrm{~mol} / \mathrm{l}$ (fig. 1). However, beyond the optimum monomer concentration, the further rise in the monomer content leads to a reduction in $\mathrm{P}_{\mathrm{s}}$. The obtained behavior is ascribed to predominance of cross-linking and compactness of the candidate polymer over $\mathrm{P}_{\mathrm{s} \text {. }}$

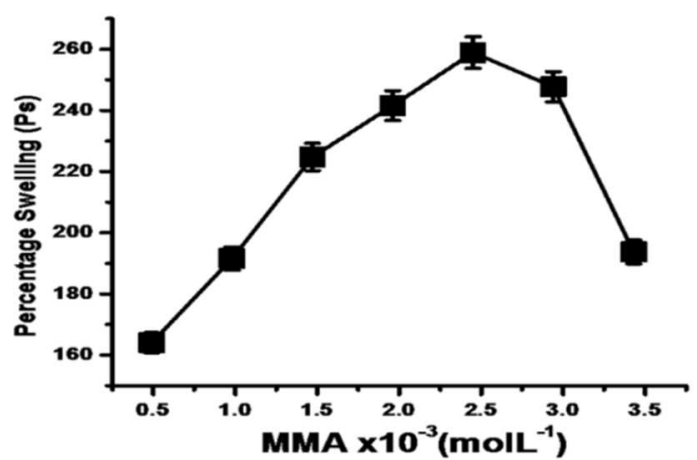

Fig. 1a: Effect of concentration of mma on Ps of synthesized ipn

\section{Characterization}

\section{Morphological analysis}

The morphological study of the backbone and IPN was carried out using SEM. SEM images of both the samples displayed changes in the surface morphology. SEM images of $g t$ revealed homogeneous surface, while gt-cl-poly (aa-ip-aam+mma) has shown morphological variation due to cross-linking present in the gt-cl-poly (aa-ip-aam mma)+(fig. 2a,b). The SEM images certainly revealed morphological differences in the characteristics of $g t$ and functionalized $g t$. The variation in surface morphologies taken place due to grafting of paa chains onto $g t$ and further interpenetrating of paam and pmma chains in the gt-cl-paa matrix resulting in the formation of ipn hydrogels. The IPN hydrogel was more compact and stable through cross-linking with glutaraldehyde [29-32].
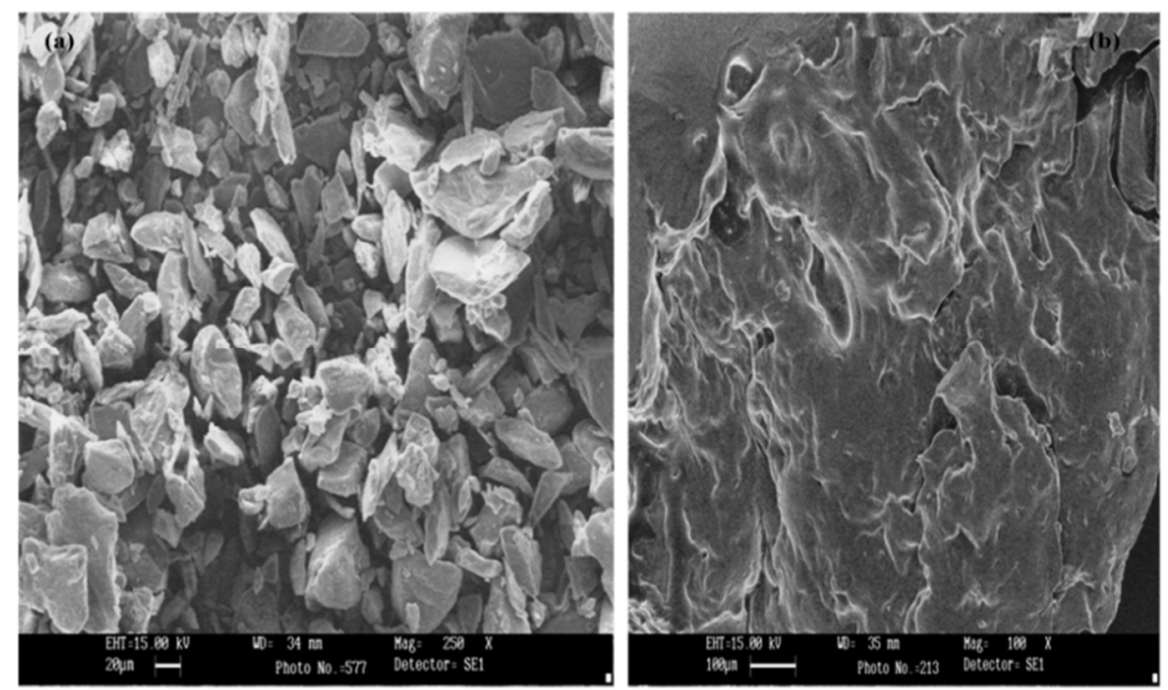

Fig. 2(a,b): SEM of (a) gt (b) gt-cl-poly(aa-ipn-aam+mma)

\section{Fourier transforms infrared spectroscopy}

FTIR spectrum of $g t$ showed peaks at $3426.92 \mathrm{~cm}^{-1}$ is due to the stretching ofO-H group of polysaccharides, $2892.89 \mathrm{~cm}^{-1}$ due to asymmetric stretching of- $\mathrm{CH}_{2}, 2500-3000 \mathrm{~cm}^{-1}$ due to $\mathrm{OH}$ of $\mathrm{COOH}, 1038.96 \mathrm{~cm}^{-1}$ due to stretching of $\mathrm{C}-\mathrm{O}$ from $\mathrm{C}-\mathrm{O}-\mathrm{C}$ vibrational stretching and peak at $642 \mathrm{~cm}^{-1}$ is due to pyranose (fig. 3a).

The additional peaks were observed in case of ipn at $1718.18 \mathrm{~cm}^{-1}$ and $1150.93 \mathrm{~cm}^{-1}$, which was due to $\mathrm{C}=0$ group of mma and $\mathrm{C}-\mathrm{O}$ stretch of ester group of monomer moiety, respectively (fig. $3 \mathrm{~b}$ ). The 


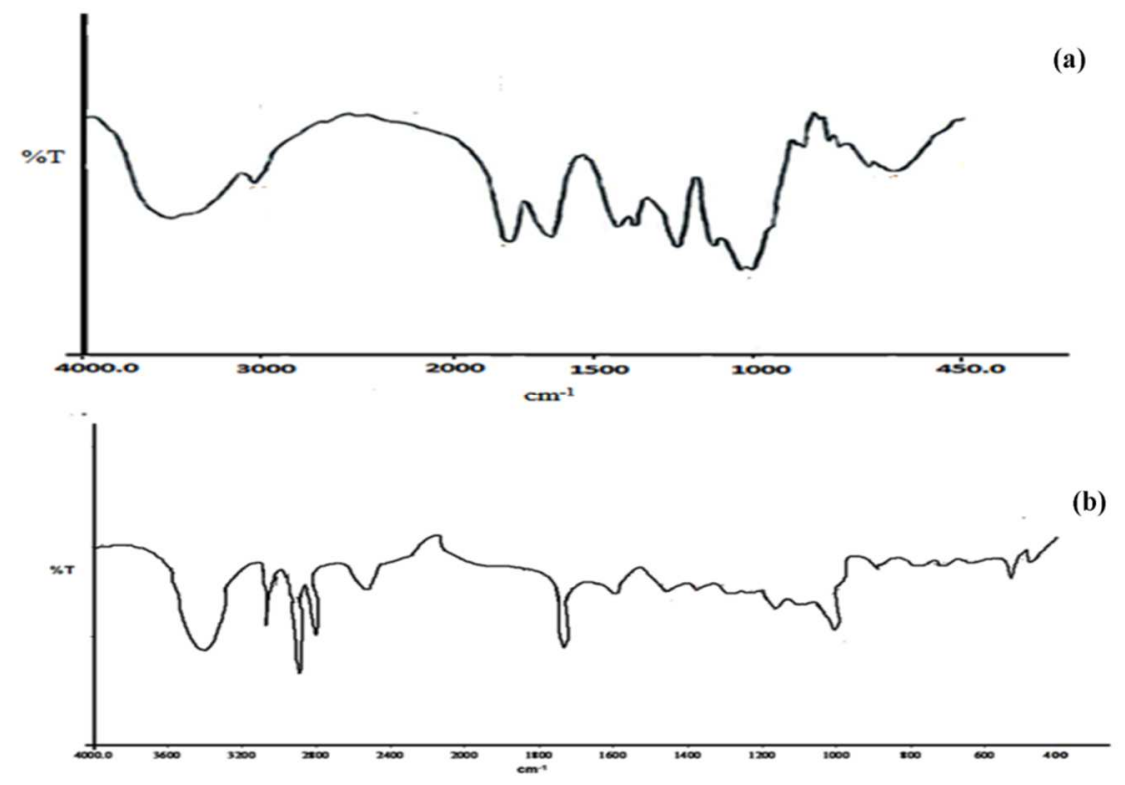

Fig. 3(a, b): FT-IR spectrum of (a) gt and (b) gt-cl-poly(aa-ipn-aam+mma)

\section{Thermal analysis}

Two stages breakdown was found in the TGA of $g t$. The first stage breakdown occurred due to the subtraction of $\mathrm{H}_{2} \mathrm{O}$ and impulsive molecules, whereas the second phase of breakdown was due to the polymer chains due to the de-polymerization reactions. The first phase breakdown appeared at a temperature from $196.9{ }^{\circ} \mathrm{C}-281{ }^{\circ} \mathrm{C}$ with $22.5 \%$ wt. loss $22.5 \%$. The second phase breakdown occurred at $479.0{ }^{\circ} \mathrm{C}$ (fig. 4a). DTG of $G t$ showed breakdown at $75.9^{\circ} \mathrm{C}$ (wt. loss $253.9 \mathrm{ug} / \mathrm{min}$ ) and 285.3
${ }^{\circ} \mathrm{C}$ (wt. loss $437.9 \mathrm{ug} / \mathrm{min}$.). DTA result gave exothermic peak at $292.1^{\circ} \mathrm{C}$ (energy loss $11.2 \mathrm{uV}$ ) (fig. 4a).

It has been observed from the fig. $4 \mathrm{~b}$ that TGA result of IPN showed early decomposition from $217.8^{\circ} \mathrm{C}$ to $281.6^{\circ} \mathrm{C}$ with $25.4 \%$ wt. loss. However, final decomposition occurred at $589.1^{\circ} \mathrm{C}$. The DTA results showed an exothermic peak at $586.1^{\circ} \mathrm{C}(53.5 \mu \mathrm{V})$ and this is in accordance with the TGA results. The DTG results showed decomposition at $269.8^{\circ} \mathrm{C}$ and $586.2^{\circ} \mathrm{C}$ with $356.3 \mu \mathrm{g} / \mathrm{min}$ and $397.7 \mu \mathrm{g} / \mathrm{min}$ weight loss, respectively. It is clearly indicated from the results that the thermal stability of synthesized IPN was higher as compared to $g t[31,32]$.

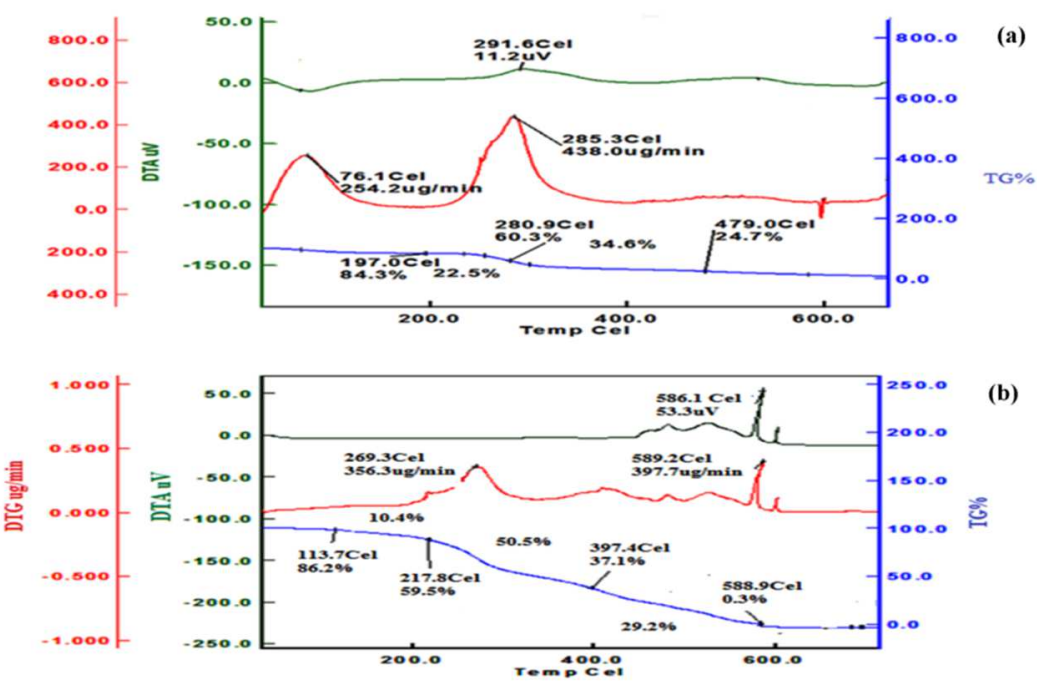

Fig. 4(a, b): TGA/DTA/DTG of (a) gt and (b) gt-cl-poly(aa-ipn-aam+mma)

\section{Pantoprazole sodium liberation through gt-cl-poly(aa-ipn- aam+mma)}

The result from one-way ANOVA and post hoc tests (table 1 and table 2) pointed that a less diffusion was observed in the drug release in the neutral medium. Similarly, no significant difference was found in neutral and acidic mediums. However, the drug release was higher in amount in basic medium.

The drug entangled in the ipn was found to be released after the dissemination of the water from the ipn, which resulted in the distension of the ipn device and liberation of the imbibed drug 
molecules. The drug diffusion started at the ipn surface, after its swelling. So, drug release was linked to the swelling characteristics the ipn matrix $[22,28]$. ipn was observed to work as a useful device for systematic liberation of the drug. It is apparent from the fig. $5 \mathrm{a}$, that IPN showed the initial release $66.08 \mathrm{ppm}$ after $30 \mathrm{~min}$. with initial diffusion coefficient i.e. $\mathrm{D}_{\mathrm{I}}=7.4$, in alkaline medium followed by $(49.98 \mathrm{ppm})$ at acidic medium i.e. $(2.0 \mathrm{pH})\left(\mathrm{D}_{\mathrm{I}}=5.3\right)$ and least release $37.96 \mathrm{ppm}$ at neutral $\mathrm{pH}\left(\mathrm{D}_{\mathrm{I}}=1.78\right)$. Equilibrium was attained after $8 \mathrm{~h}$ with maximum release $1033.21 \mathrm{ppm}$ followed by $959.65 \mathrm{ppm}$ and $757.89 \mathrm{ppm}$ at alkaline, neutral and acidic $\mathrm{pH}$, respectively. The drug liberation kinetics showed that the drug liberation behavior increased with increased in $\mathrm{pH}$. This behavior can be discussed on the fact that at acidic $\mathrm{pH},-\mathrm{COOH}$ groups present in unionized form, this leads to the distortion of the IPN matrix. As

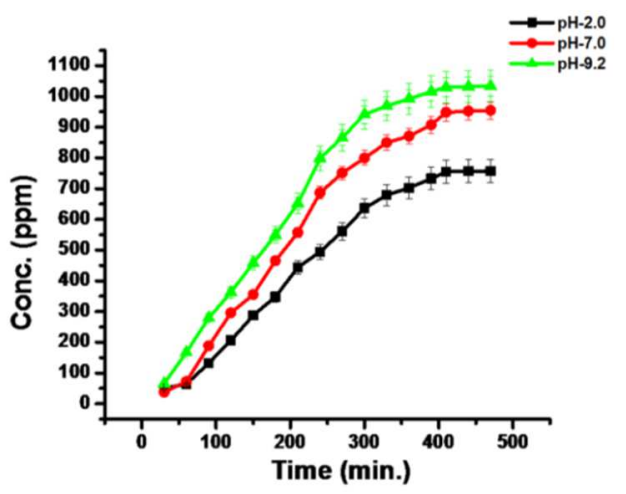

5 a

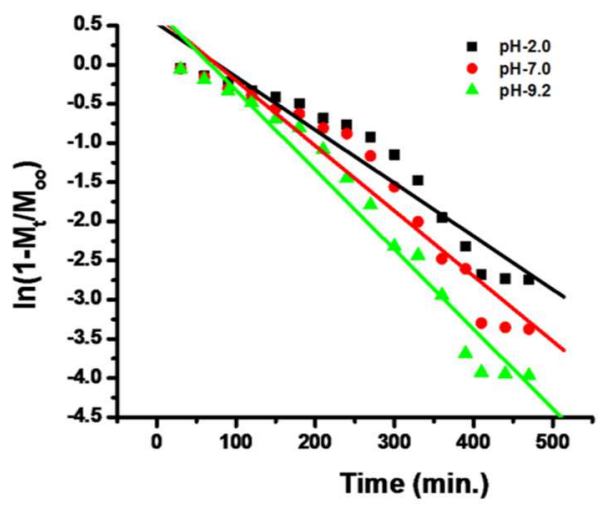

$5 c$ the $\mathrm{pH}$ increases- $\mathrm{COOH}$ ionize to-COO-and thus, keep away from one another leads to increase the pantoprazole sodium liberation from IPN device. Drug liberation showed non-fickian diffusion mechanism at alkaline $\mathrm{pH}$, Case II diffusion at acidic and neutral $\mathrm{pH}$ (table 3). This clearly indicated that in alkaline medium drug liberation rate is similar to the relaxation time of ipn device. Whereas, in acidic and neutral media, drug liberation was faster as compared to the relaxation time of the ipn. The value of gel characteristics constant i.e. ' $\mathrm{K}$ ' was greater at alkaline $\mathrm{pH}$, which revealed that highest drug liberation occurred at $\mathrm{pH}$ 9.2. $\mathrm{D}_{\mathrm{I}}$ has lesser value as compared to $\mathrm{D}_{\mathrm{L}}$, this showed slower drug liberation in the initial stage than the lateral stage [32]. All the experiments were carried-out in triplicate, so as to maintain the accuracy and reproducibility.

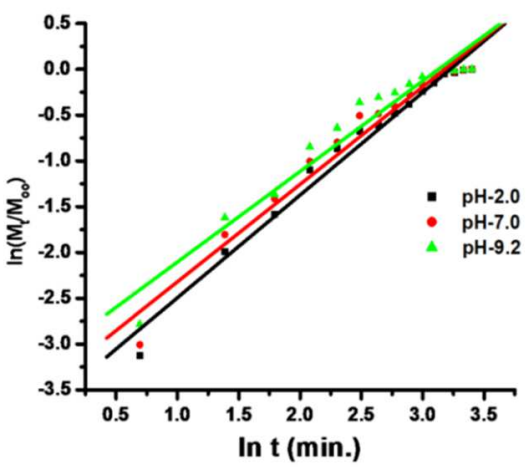

$5 b$

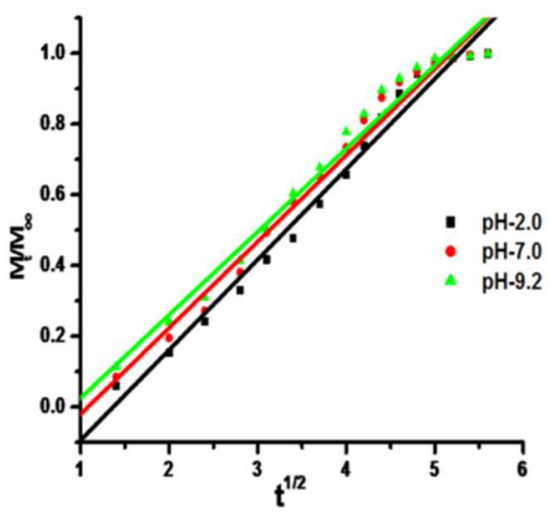

Fig. 5(a-d): Effect of pH onto pantoprazole sodium release behavior through gt-cl-poly(aa-ipn-aam+mma), (a) conc. vs time, (b) ln(1$M_{t} / M_{\infty}$ ) vs time, (c) $M_{t} / M_{\infty} v s t^{1 / 2}$ and (d) $\ln M_{t} / M_{\infty} v s$ lnt

Table 1: Oneway ANOVA model of the drug release

\begin{tabular}{lllll}
\hline & Sum of squares & Df & Mean square & Sig. \\
\hline VAR0001 Between & 544610.5 & 2 & 272305.8 \\
Groups Within & 2355461 & 42 & 56082.426 \\
Groups Total & 2900073 & 44 & & .012 \\
\hline
\end{tabular}

Values are expressed as mean $(n=3)$. The drug release significantly varies with the pH level $(F=4.76, P=0.012)$.

Table 2: Post Hoc Test for the drug release behavior

\begin{tabular}{|c|c|c|c|c|}
\hline (I)VAR00002 & (J)VAR00002 & Mean Difference(I-J) & Std. Error & Sig. \\
\hline \multirow[t]{2}{*}{1.0} & 2.00 & -60.421 & 86.43 & .76 \\
\hline & 3.00 & $-257.680^{*}$ & 86.43 & .012 \\
\hline \multirow[t]{2}{*}{2.0} & 1.00 & 60.421 & 86.43 & .76 \\
\hline & 3.00 & -197.210 & 86.47 & .070 \\
\hline \multirow[t]{2}{*}{3.0} & 1.00 & $257.680^{*}$ & 86.47 & .013 \\
\hline & 2.00 & 197.210 & 86.47 & .070 \\
\hline
\end{tabular}

Values are expressed as mean $(n=3)$. 
Table 3: Diffusion exponent, Gel characteristic constant and diffusion coefficient of pantoprazole sodium release behavior through loaded gt-cl-poly (aa-ipn-aam+mma)

\begin{tabular}{|c|c|c|c|c|c|c|}
\hline \multirow[t]{2}{*}{ Sample } & \multirow[t]{2}{*}{$\mathbf{p H}$} & \multirow[t]{2}{*}{ Diffusion exponent ' $n$ ' } & \multirow[t]{2}{*}{ Gel characteristic constant ' $K$ ' $\times 10^{-2}$} & \multicolumn{3}{|c|}{ Diffusion coefficient $\left(\mathrm{m}^{2} / \mathrm{hrs}\right) \times 10^{-7}$} \\
\hline & & & & $\mathbf{D}_{\mathrm{I}}$ & $\mathbf{D}_{\mathrm{A}}$ & $\mathbf{D}_{\mathrm{L}}$ \\
\hline \multirow[t]{3}{*}{ Gt-cl-poly(AA-ipn-AAm+MMA) } & 2.0 & 0.886 & 0.049 & 5.358 & 0.2355 & 23.4 \\
\hline & 7.0 & 0.863 & 0.064 & 1.784 & 0.1062 & 10.7 \\
\hline & 9.2 & 0.868 & 0.056 & 7.400 & 0.2784 & 19.6 \\
\hline
\end{tabular}

Values are expressed as mean $(n=3)$, Where, $D_{I}, D_{A}$ and $D_{L}$ are the initial, average and later diffusion coefficient respectively

\section{CONCLUSION}

gt, paa and mma based crosslinked IPN were synthesized using lipase-glutaraldehyde as initiator-crosslinker system. FTIR analysis proved the successful graft co-polymerization of vinyl monomers onto $g t$. Moreover, thermal analysis showed that ipn were more stable than the pristine $g t$. The synthesized ipn possessed the desired swelling capacity required for the controlled drug delivery and was $\mathrm{pH}$ sensitive, when used in the systematic liberation of pantoprazole sodium at $37^{\circ} \mathrm{C}$. The result revealed that the $\mathrm{D}_{\mathrm{L}}$ was higher as compared to $\mathrm{D}_{\mathrm{I}}$, demonstrating that pantoprazole sodium liberation rate was larger in the lateral stages. The foregone discussion showed that the prepared ipn could be used as prospective carrier for prolonged drug delivery.

\section{ACKNOWLEDGEMENT}

Author is thankful to CT Group of Institutions, Jalandhar for carrying-out the research work.

\section{AUTHORS CONTRIBUTIONS}

Synthesis work was done by Dr Saruchi and Drug kinetics was done by Dr Vaneet Kumar

\section{CONFLICT OF INTERESTS}

All authors have none to declare

\section{REFERENCES}

1. Pawar SK, Pawar PS, Patel VA. Microbial polysaccharides in colon specific drug delivery. Int J Pharma Sci Rev Res 2011;6:188-96.

2. Kumar SNA, Pavanveena C, Kavitha K. Colonic drug delivery system of trimethazidine hydrochloride for angina pectoris. Int J Pharm Pharm Sci 2011;3:22-6.

3. Wang W, Wang A. Synthesis and swelling properties of $\mathrm{pH}$ sensitive semi-IPN superabsorbent hydrogels based on sodium alginate-g-poly (sodium acrylate) and polyvinylpyrrolidone. Carbohydrate Polymers 2010;80:1028-36.

4. Hua SB, Wang AQ. Synthesis, characterization and swelling behaviors of sodium alginate-g-poly (acrylic acid)/sodium humate superabsorbent. Carbohydrate Polymers 2009;75:7984.

5. Jin SP, Liu MZ, Zhang F, Chen SL, Niu AZ. Synthesis and characterization of $\mathrm{pH}$-sensitivity semi-IPN hydrogel based on hydrogen bond between poly ( $\mathrm{N}$-vinylpyrrolidone) and poly (acrylic acid). Polymer 2006;47:1526-32.

6. Kabiri K, Omidian H, Hashemi SA, Zohuriaan-Mehr MJ. Synthesis of fast-swelling superabsorbent hydrogels: effect of crosslinker type and concentration on porosity and absorption rate. Eur Polymer J 2003;39:1341-8.

7. Wang $\mathrm{W}$, Wang $\mathrm{Q}$, Wang A. pH-responsive carboxymethylcellulose-g-poly(sodium acrylate)/polyvinylpyrrolidone semi-IPN hydrogels with enhanced responsive and swelling properties. Macromol Res 2011;19:57-65.

8. Gupta P, Vermani K, Garg S. Hydrogels: from controlled release to $\mathrm{pH}$-responsive drug delivery. Drug Discovery Today 2002; 7:569-79.

9. Hennink WE, Nostrum CFV. Novel crosslinking method to design hydrogels. Adv Drug Delivery Rev 2002;54:13-26.

10. Gils PS, Ray D, Mohanta GP, Manavalan R, Sahoo P. Designing of new acrylic based macroporous superabsorbent polymer hydrogel and suitability for drug delivery. Int J Pharm Pharm Sci 2009;1:43-54.

11. Hekmat A, Barati EV, Frahani A, Afraj S. Synthesis and analysis of swelling and controlled release behavior of anionics IPN acrylamide based hydrogels. World Academy Sci Eng Technol 2009;56:96-100.

12. Wang W, Wang A. Preparation, swelling and water-retention properties of crosslinked superabsorbent hydrogel based on guar gum. Adv Mater Res 2010;96:177-82.

13. Peppas NA, Bures P, Lepbandung W, Ichikawa H. Hydrogels in pharmaceutical formulations. Eur J Pharm Biopharm 2000;50:27-46.

14. Lin CC, Metters AT. Hydrogels in controlled release formulations; Network design and mathematical modeling. Adv Drug Delivery Rev 2006;58:1379-408.

15. Kowshik K, Vishal GN, Gowda DV, Praveen S. Formulation of immediate release (IR) atorvastatin calcium pellets and sustained release (SR) glibenclamide for fixed-dose combination dosage form. Asian J Pharma Clin Res 2018;11:159-65.

16. Insan SK, Iyan S, Nasrul W, Dasty LF, Rahadianti UP. Application and characterization of in situ gel. Int J Appl Pharm 2018;10:34-7.

17. Ruchi SS, Gowda DV, Vishal GN, Praveen S, Manjunath M. Formulation development and evaluation of almond gum based sustained release matrix tablet of indomethacin. Asian J Pharma Clin Res 2018;11:166-9.

18. Anas TA, Ali KA. Formulation and in vitro evaluation of amlodipine gastroretentive floating tablets using a combination of hydrophilic and hydrophobic polymers. Int J Appl Pharm 2018;10:119-25.

19. Tamar T, Yachin C, Joseph K. Characterization of glucosesensitive insulin release systems in simulated in vivo conditions. Biomaterials 2000;21:1679-87.

20. Saruchi, Kaith BS, Jindal R, Kapur GS, Kumar V. Synthesis, characterization and evaluation of gum tragacanth and acrylic acid hydrogel for sustained calcium chloride releaseenhancement of water holding capacity of soil. J Chin Adv Materials Soc 2014;2:40-52.

21. Anderson DMW, Weiping $\mathrm{W}$. The tree exudates gum permitted in foodstuffs as emulsifiers, stabilizers and thickeners. Biol Agric Horticulture 1985;2:329-34.

22. Saruchi, Kaith BS, Jindal R, Kumar V. Adsorption of crude oil from aqueous solution using gum tragacanth polyacrylic acid based hydrogel. Pet Sci Technol 2015;33:278-86.

23. Prashar D, Kaith BS, Kalia S, Sharma S. Synthesis, characterization and evaluation of electrical stimulus sensitive behavior of Gt-cl-poly (AA) superabsorbent hydrogel. Int J Pharm Pharm Sci 2012;4:419-23.

24. Weiping W, Branwell A, Essex CL. Tragacanth and karaya, Woodhead Publishing Limited and CRC Press LLC; 2000.

25. Saruchi, Kaith BS, Jindal R, Kapoor GS. Enzyme-based green approach for the synthesis of gum tragacanth and arylic acid crosslinked superabsorbent-its utilization in controlled fertilizer release and enhancement of water holding capacity of soil. Iranian Polymer J 2013;22:561-70.

26. Kaith BS, Saruchi, Rajeev J, Bhatti MS. Screening and RSM optimization for synthesis of a gum tragacanth-acrylic acid based device for in situ controlled cetirizine dihydrochloride release. Soft Matter 2012;8:2286-93.

27. Saruchi, Kaith BS, Jindal R, Kumar V, Bhatti MS. Optimal response surface design of Gum tragacanth based poly[(acrylic acid)-coacrylamide] IPN hydrogel for controlled release of 
antihypertensive drug losartan potassium. RSC Adv 2014;4:39822-9.

28. Khare AR, Peppas NA. Release behaviour of bioactive agents from pH-sensitive hydrogels. J Biomater Sci Polym Ed 1993;4:275-89.

29. Saruchi, Kaith BS, Kumar V, Jindal R. Biodegradation study of enzymatically synthesized interpenetrating polymer network: evaluation of agrochemical release and impact on soil fertility. Biotechnol Reports 2016;9:74-81.
30. Mohamadnia Z, Zohuriaan Mehr MJ, Kabiri K, Razavi Nouri M. Tragacanth gum-graft-polyacrylonitrile: synthesis, characterization and hydrolysis. J Polym Res 2008;15:73-180.

31. Saruchi, Kaith BS, Jindal R, Kumar V. Biodegradation of gum tragacanth acrylic acid based hydrogel and its impact on soil fertility. Polym Degrad Stab 2015;115:24-31.

32. Singh B, Sharma DK, Gupta A. In vitro release dynamics of thiram fungicide from starch and poly(methacrylic acid) based hydrogels. J Hazard Mater 2008;154:1-3. 